\title{
Effect of Job Stressors Onjob Performance of Lecturer Physical Education; Mediating Role of Coping Mechanism (Relaxation Coping)
}

\author{
Muhaamad Asghar Khan ${ }^{1}$, Azmat Ali Shah², Afshan Jabeen", Mehwish Manzoor ${ }^{1}$ \\ ${ }^{1}$ Institute of Physical Education, Gomal University, DI Khan, Pakistan \\ ${ }^{2}$ Department of Political Science, Qurtuba University, DI Khan, Pakistan \\ Email address: \\ asgharkhan.bannu@gmail.com (M. A. Khan),dr.azmat@qurtuba.edu.pk (A. A. shah), ajmalik54@gmail.com (A. Jabeen), \\ mehwishmanzoor@yahoo.com (M. Manzoor)
}

\section{To cite this article:}

Muhaamad Asghar Khan, Azmat Ali Shah, Afshan Jabeen, Mehwish Manzoor. Effect of Job Stressors Onjob Performance of Lecturer Physical Education; Mediating Role of Coping Mechanism (Relaxation Coping). International Journal of Science, Technology and Society. Vol. 10, No. 2, 2021, pp. 107-112. doi: 10.11648/j.ijsts.20211002.18

Received: December 22, 2020; Accepted: January 15, 2021; Published: April 7, 2021

\begin{abstract}
The aim of the study was to investigate the effect of job stressors on job performance with mediating role of coping mechanism. The finite Population of the study comprised of 73 female and 97 male physical education lecturers' serving in government colleges of Khyber Pakhtunkhwa, Pakistan. Three different types of self-administered cum close-ended questionnaires such as Job Stressors, Job Performance and Coping Mechanism were used for the data collection. Face and content validity was done from the export in the relevant field. To assess the feasibility of the tool; the researcher conducted a small scale preliminary study i.e. a pilot study with 25 lecturers physical education (13 male and 12 female), the subgroup of the intended population. Mean, stander deviation, multiple regressions and Pearson's correlation coefficient used to test the hypotheses. The process v3.3 by Andrew F. Hayes was used for mediation. Results of existing study highlighted that there is a positive and significant relationship and effect among job stressors, job performance and relaxation coping ( $\mathrm{r}=.662$; $939 \&$ $\mathrm{p}=.000<.01$ ). The mediating role of relaxation coping was found greater and partial. The researcher concluded that there is partial mediating role of relaxation coping between job stressors and job performance of the lecturer's physical education at collage level in KP Pakistan. The researcher recommended that the lecturer physical education may ensure the contribution of the relaxation coping mechanism for the purpose to improve their job performance at college level.
\end{abstract}

Keywords: Job Stressors, Job Performance, Relaxation Coping

\section{Introduction}

Occupational stress is a very common state and often found in every workplace. Occupational stress results in dissatisfaction among employs. It makes them feel extremely tired. Their work performance and interpersonal relationships are badly affected. Occupational stress is directly linked with job satisfaction; six aspects of job satisfaction have a negative association with occupational stress. Controlling factors like co-workers, Work, pay, supervision, Promotion and Job in Genera [16]. Job stress is a universal phenomenon which is badly affecting the institution in general and teachers in particular [8]. Job stress is changing the response of an individual to such a situation that creates disturbance in different parts of the profession [9]. Moderate stress can prompt good quality like motivation, improvement in performance and achievement as well, but it continues over a longer period, then psychological problems, badly affecting human body and mind are created [27].

The working condition can be viewed from a variety of perspectives. Generally, the physical and psychological aspects of the workplace are known as working condition. Working life has great importance for each individual. It affects the well-being of a person and helps him/her to develop skills, build social relation and earn a living. It can also be hazardous for them due to its physical and psychosocial aspects [15]. There has been an increase in the workload of teachers' after the decentralization. Apart from lesson planning and teaching, they have to perform some other functions as well. They remain involved in curriculum 
development. They have to monitor the progress of the students at least once in a semester where the academic performance and social development of the student are discussed [6]. Excessive workload is a factor which can cause stress in an individual within given period of time [11]. Workload means the number of various activities over which an employee has to spend time [12]. Work overload and under load are such job-related factors that can generate pessimism in employees resulting in depression, poor performance and lack of motivation [2]. Resource means the teaching method and material, time available for instruction, knowledge and skill that teachers acquire through training and experience. Teaching pupils with special need in the classroom is different than teaching in a regular program [22]. More instruction time; another learning method and professional knowledge are required for the students with special needs. This can be done if resources are increased or rearranged [18]. Children with special needs should meet the classroom needs. Physical education teacher engages the students in physical exercise, play, recreation, sport and game to develop their physical fitness to improve their motor activity [20]. The responsibility of physical education teachers in an organizational institution is to organize and arrange physical activity and psychomotor learning. In primitive time physical education teachers were just considered as a physical instructor. Taking the class is also the primary responsibility of physical education teachers [21]. Physical education teachers perform their job as a motivator; they make the pupil think critically about the cultural and social significance of the physical activities, understand the influences that engage the people in physical activities [5]. Physical education teachers take practical classes and engage the students in physical activity in an educational organization, which has a positive impact on their cognitive skill and academic performance [17].

Unfortunately, health, physical education, recreation and sport have never gained the statement of the "importance" among the disciplines in most of the EAST excluding a few like China, Japan, Malaysia etc; Facts behind may be money but the most dominant in the area of physical education and sports seems to be lack of interest/ ignorance from the ruling class as well as intellectuals. The season or the arguments is that even the first quarter of the 21 st century is in its settlements we don't see any sparkling personality in the area of applied research from this part in Pakistani perspective in the field. In the present, the researcher has attempted to understand the job stressors and its effect on the performance of job of the respondent. To neutralize the effects, the researcher has select relaxation method as a coping mechanism between job stressors and job performance. In Pakistan, context research study has not been conducted so far regarding job stressors and job performance of lecturer of physical education along with the mediating role of coping mechanism. LPEs have more responsibilities than other lecturers such as the teaching of the theory classes, conducting practical and organizing of sports events and maintenance of discipline. These responsibilities create stress and tensions which are ultimate create poor job performance. The study was a first attempt to probe the in hand issue on ground reality at this research article. In this perspective, LPEs has facing more stressors (workload, working environment, physical recourse) which affect their performance due to such a burden. So the researcher intended to check the mediating role of relaxation as coping mechanism.

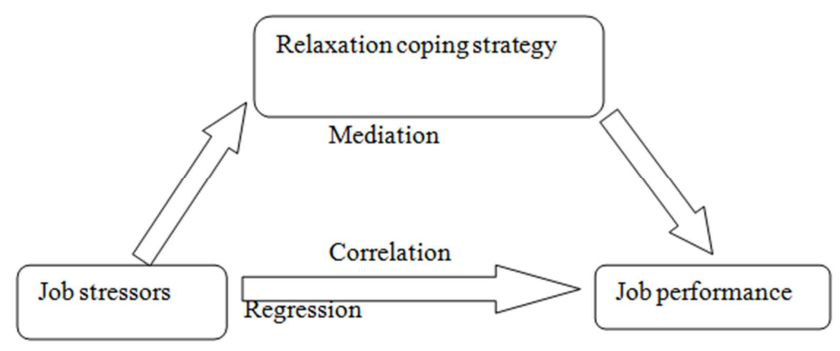

Figure 1. Theoretical framework

\section{Methods and Materials}

The aim of the present study was to investigate the effect of job stressors on job performance with mediating role of coping mechanism (relaxation coping). The researcher adopted quantitative approach with cross-sectional research. Quantitative study is an appropriate approach to determine objective measurement and the mathematical, numerical and statistical analyses of the collected data through research instrument and surveys [1]. The present study was exploratory particularly descriptive in nature. Population of this study consists of 73 female and 97 male physical education lecturers' working in government colleges of KP, Pakistan. The researcher developed three different types of self-administered cum close-ended questionnaires with the help of supervisor and literature review. In current research study job stressors (workload, working environment and physical resources) was the independent variable. Coping mechanism (relaxation coping) was the mediating variable, and job performance was the dependent variable. To assess the feasibility of the tool; the researcher conducted a small scale preliminary study i.e. a pilot study with 25 lecturers physical education (13 male and 12 female), the subgroup of the intended population. The initially developed questionnaire was distributed among the experts in the relevant field (social sciences) for validity. Some of the items were deleted in the response of the experts with the consultation of the research supervisor. There were 65 items in the questionnaire while after the process of validation; the total 51 items remained in the final version. The Cronbach's alpha reliability job stressor questionnaire appears as.786 for coping mechanism questionnaire.882 and for job performance questionnaire.862. Descriptive and inferential statistical techniques Mean, multiple regressions and Pearson's correlation coefficient were used to test the hypotheses while the process v3.3 by Andrew F. Hayes was used for mediation.

\section{Analysis}

The table 1 show the descriptive statistics of research variables before calculate the association. The table found that the mean of job stressors was $3.53 \pm .470$, relaxation coping was $3.49 \pm .701$ and job performance was $3.53 \pm .689$. The total number of respondents (Lecturer physical education) 
Table 1. This Table shows the descriptive statistics of research variables before calculate the association.

\begin{tabular}{llll}
\hline Research Variables & Mean & Std. Deviation & N \\
\hline Job Stressor & 3.5280 & .47070 & 151 \\
Relaxation & 3.4907 & .70123 & 151 \\
Job Performance & 3.5340 & .68919 & 151 \\
\hline
\end{tabular}

H1: There is positive association among job stressors, job performance and mediating variables

Table 2. This Table Showing the results of the hypothesis there is a significant relationship between job stressors, coping mechanism.

\begin{tabular}{lllll}
\hline Research Variables & & Job Stressor & Relaxation & Job Performance \\
\hline \multirow{3}{*}{ Job Stressor } & Pearson Correlation & 1 & & \\
& Sig. (2-tailed) & & & \\
& $\mathrm{N}$ & 151 & & \\
Relaxation & Pearson Correlation & $.632^{* *}$ & & \\
& Sig. (2-tailed) & .000 & & \\
& $\mathrm{~N}$ & 151 & $.939^{* *}$ & .000 \\
Job Performance & Pearson Correlation & $.662^{* *}$ & .000 & .000 \\
& Sig. (2-tailed) & .000 & 151 & 151 \\
\hline
\end{tabular}

$\mathrm{H} 2$ : The job stressors have significant impact on Job performance

The above Table 2 showing the results of the hypothesis there is a significant relationship between job stressors, coping mechanism and job performance of lecturer physical education at the college level in KP, Pakistan. Hypothesis testing the association between independent, mediators and dependent variables, The $\mathrm{R}$ (Correlation values) and $\mathrm{p}$ (Significant values showed. the last row of the table is more understandable and valuable for readers to find out the relationship of all research variables. There was strong association between relaxation coping and job performance $(\mathrm{R}=.939 \& \mathrm{P}$-value $=.000<.01)$ in the same way rest of research variables job stressors $(\mathrm{R}=.662$ $\&$ P-value $=.000<.01$ ), the analysis of correlation shows that relaxation coping highly correlated with the job performance of lecturer physical education. The researcher concluded from the above-mentioned statistics that the hypothesis H1: there is a significant relationship of job stressors, coping mechanism and job performance of lecturer physical education at college level in KP, Pakistanis hereby accepted.

Table 3. Regression Analysis (Model Summary).

\begin{tabular}{lllllll}
\hline Model & R & R Square & Adjusted R Square & Std. Error of the Estimate & F & Sig. \\
\hline 1 & $.954^{\mathrm{a}}$ & .910 & .908 & .20953 & 369.229 & .000 \\
\hline
\end{tabular}

a. Predictors: (Constant)

b. Dependent Variable: occupational Performance

H3: There is a significant role of relaxation coping strategy in-between job stress and job performance

The First Step in Mediation (a)

Table 4. The Coefficientsof regression.

\begin{tabular}{|c|c|c|c|c|c|}
\hline \multirow{2}{*}{ Model } & \multicolumn{2}{|c|}{ Unstandardized Coefficients } & \multirow{2}{*}{$\begin{array}{l}\text { Standardized Coefficients } \\
\text { Beta }\end{array}$} & \multirow{2}{*}{$\mathbf{T}$} & \multirow{2}{*}{ Sig. } \\
\hline & B & Std. Error & & & \\
\hline (Constant) & .019 & .131 & & .145 & .000 \\
\hline occupational Stressor & .190 & .049 & .062 & 1.829 & .019 \\
\hline
\end{tabular}

a. Dependent Variable: occupational Performance

The table showing the results of hypothesis the predictors occupational stressors have significant impact on criterion (occupational performance of lecturer physical Education), the hypothesis testing the predictability of Criterion (occupational performance) by predictors (Job stressors. Multiple regression test was utilized to reach at facts about the predictive power of Job stressors. The $\mathrm{R}$ square (coefficient of determination) appears as $\mathrm{R} 2=.910$ which indicates that there was $91 \%$ variation which supported by the p-values of predictors. The multiple regression results shows that occupational stressors ( $\mathrm{p}$-value=.019). The causen-effect results also support and validate the results of correlation where the relationship between the job stressors and job performance. Therefore from the above-given statistics concluded that the hypothesis $\mathrm{H} 2$ : The significant effect of predictors (Job stressors) mediator (coping mechanism) on Criterion (Job performance of lecturer physical Education) at the colleges of KP, Pakistan hereby 
accepted.

Table 5. Model Summary.

\begin{tabular}{lllllll}
\hline $\mathbf{R}$ & R Square & MSE & F & df1 & df2 & P \\
\hline .6322 & .3997 & .2972 & 99.2052 & 1.0000 & 149.000 & .0000 \\
\hline
\end{tabular}

Table 6. The Coefficients of Regression.

\begin{tabular}{lllllll}
\hline Model & Coefficient & Se & T & P & LLCI & ULCI \\
\hline Constant & .1678 & .3365 & .4987 & .6187 & -.4972 & .8329 \\
Job stressor & .9418 & .0946 & 9.9602 & .0000 & .7550 & 1.1287 \\
\hline
\end{tabular}

Independent Variable: Job stressors

Dependent Variable: Relaxation (Coping mechanism)

The second \& Third Step in Mediation $(b \& c)$

Table 7. Model Summary.

\begin{tabular}{lllllll}
\hline R & R Square & MSE & F & df1 & df2 & P \\
\hline .9434 & .8900 & .0529 & 598.9614 & 2.0000 & 148.000 & .0000 \\
\hline
\end{tabular}

Table 8. Coefficient of Regression.

\begin{tabular}{lllllll}
\hline Model & Coefficient & Se & T & P & LLCI & ULCI \\
\hline Constant & -.0278 & .1422 & -.1956 & .8452 & -.3087 & .2531 \\
Job stressor & .1657 & .0515 & 3.2178 & .0016 & .0640 & .2675 \\
Relaxation & .8529 & .0346 & 24.6661 & .0000 & .7845 & .9212 \\
\hline
\end{tabular}

Independent Variable: Job stressor and Relaxation (Coping mechanism)

Dependent Variable: Job Performance

The forth Step in Mediation (c)

Table 9. Model Summary.

\begin{tabular}{lllllll}
\hline R & R Square & MSE & F & df1 & df2 & P \\
\hline .6618 & .4380 & .2627 & 116.1224 & 1.0000 & 149.0000 & .0000 \\
\hline
\end{tabular}

Table 10. Coefficient of Regression.

\begin{tabular}{lllllll}
\hline Model & Coefficient & Se & T & P & LLCI & ULCI \\
\hline Constant & .1153 & .3200 & .3603 & .7191 & -.5171 & .7477 \\
Job stressor & .9690 & .0899 & 10.7760 & .0000 & .7913 & 1.1467 \\
\hline
\end{tabular}

Independent Variable: Job stressor

Dependent Variable: Job Performance

The below-mentioned tables were produced by the Process Model to test the mediating role of relaxation (coping mechanism) in between job stressors and job performance of lecturers' physical education. Four different step were performed by the process model ( $\mathrm{a}, \mathrm{b} \& \mathrm{c}$, and Ć) the first step of mediation indicates with the production of path.(a) that in the relaxation coping (coping mechanism) there is (39\%) variation mediator is due to the job stressors (predictors). Likewise, it too depict significant and positive impact of job stressors on relaxation (coping mechanism) $(\beta=0.94$ while $p=.000)$. Similarly, the path $\mathrm{b} \& \mathrm{c}$ which was the third step of mediation indicates that in the dependent variable (job performance of lecturer physical education) there is $89 \%$ variation is due to the predictors (job stressor and relaxation coping mechanism). In the same way the table also shows that there is too statistically. Significant effect of relaxation (coping mechanism) on job performance of the lecturer physical education $(\beta=0.85$ while $p=.000)$ and job stressor on job performance of the lecturer physical education
( $\beta=0.16$ while $p=.000$ ) the bootstrapping run to create the $95 \%$ confidence intervals for two parameters where lower limit confidence interval denoted as LLCI and upper limit confidence interval denoted as ULCI.

The path (c) was the fourth step of mediation which indicates that there is $43 \%$ difference in the independent variable (job performance of lecturer physical education is due to predictor (job stressors). In the same way, it indicates that there is a positive and significant relationship between job stressor and job performance of lecturers physical education $((\beta=0.9690$ while $p=.000)$. usually, the decision for four paths about mediation was made by the researcher on significant $\mathrm{p}$-value to decide about the mediation. But due to the significance of all paths in the current mediation model the researcher used coefficient value to decide about the mediation. It is indicated thatrelaxation (coping mechanism) partially mediates the association between job stressors and job performance of lecturer physical education. Theworth of coefficient reduces and the connection remains positive between job stressors and job performance of lecturer physical education after entering relaxation as a mediator (0.85). Finally, It is determined that the $1^{\text {st }}$ model of mediation is partial mediation.

Table 11. Sobel Test.

\begin{tabular}{llll}
\hline Coefficient & Se & $\mathbf{Z}$ & P \\
\hline .2405 & 0.087 & 9.2311 & .0000 \\
\hline
\end{tabular}

For the confirmation of mediation in between research variables (DV, IV, MV) the Process procedure also provides the normal theory test or Sobel test. The attention of this analysis is likely to be on indirect effect (mediation effect) which in some places can also be calculated as the difference between $\mathrm{c}$ and $\mathrm{c}^{\prime}$. The (Table 11) delivers the output of Sobel test in which effect size is (.2405) which is statistically, greater than 0/zero with 0.05 level of confidence. Similarly, Significant P-value (.000) where $(\mathrm{P}<.05)$ depicts that the mediating effect highlighted in between the research variables, Therefore the P-value is significant and hence it can be found that relaxation (coping mechanism) mediates the association between the job stressors and job performance of lecturer physical education.

\section{Results}

The first mediation model Job stressors, relaxation coping and job performance (X-M1-Y), the Beta weight of $\mathrm{C}$ (director impact) is.9690 while Ć gives B weight of.1657 with the addition of mediator "relaxation coping" (path. B). while the Beta weight for independent variable has decreased from (.9690) to (.1657) although, since Ć has not become insignificant, while, the overall Beta weight will be 1.01 $(.1657$ C +.8529 B) after mediation, that indicates that mediator has supported the connection between criterion and predictor variable via partial mediation. Hence the hypothesis is validated. A Bird-eye view of three mediation models (M1= Relaxation coping) has played an interfering role in relations between job stressor and job performance of $\mathrm{L}$. P. Es at the college level in KP, Pakistan. It is concluded by the results that the strongest mediation model was Model 1 (Job 
stressors, relaxation coping and job performance) which was considered to be the pivotal coping mechanism to human relationship in comparison to other coping. Since the $r 2$ for model 1 was recorded as.3997 and B was.8529.

\section{Discussion}

The current research study was carryout to evaluate the effect of job stress on job performance of LPE to highlight the mediating role relaxation coping. All the hypotheses were accordingly presented and analyzed in the analysis portion. The first hypothesis declared that there is a significant and positive relationship among the job stress, job performance and relaxation. The respondents were agreed that job stress (working environment, work load and physicalre sources) are the factors which are associated with their job performance and hence the data analysis indicate that there significant and positive correlation between job stress and job performance. The same result was indicated different studies i.e. workplace and infrastructure positive and negative effect on the performance of employees [1]. Working environment is a factor for eu-stress among the teachers and positive association with job performance [3]. The author further declared that marital and economic factors are the main causes of stress and have positive association with job performance of teachers. The role of organization job insecurity and uncongenial working condition are major sources of stress which have negative and positive association with working proficiencies and abilities of employees [13]. On the basis of second hypothesis, the analyze data revealed that job stress has significant and positive impact on the job performance due to coping mechanism. The existing result is also supported by various studies. Stress affects the ability and capability of the teachers [14]. Poor relation with a boss, thwarted ambition, role ambiguity, job insecurity is sources of stress which have an egative effect on the teaching performance of the teachers and administrators [23]. The finding of this current study indicated that relaxation coping strategy play their significant mediating role in-between job stressors (workload, working environment, existing resources) and job performance (classroom teaching, field teaching, conducting sports, discipline maintenance ) of LPEs at college level in KP, Pakistan. Physical education teachers should know about the balance and training and apply them in practice, these training ideas can improve stability of individual exercise, balance and control of the different muscle groups during physical activity and coordination [19]. The teaching of various subjects depends upon the teaching tools and resources in classrooms such as audio and visual aids, which makes the teaching more effective [24]. Management of the different unrealistic aspects is the key ability of a teacher to express in a shape of visual aids and verbal reports, while it enables the process of teaching easy, stable and entertaining, which is a complicated task [26]. In the contemporary age everyone particularly teacher is facing or the victim of stresses such as competitions, domestic issues, violence and environment, but seeking pleasure and ignorance as well as avoiding pain is the inborn tendency of human [4].
Facing of the un-pleasure situation and remain happy are being possible through coping strategies. Awareness about mediators, stressors and coping mechanism are the helpful tools to overcome and reduce the effect and burnout of stress [7]. Selection expenses and increase of staff, good performers may be resulting, when tension and stress are properly managed and addressed. Leisure actions are also an important and positive relaxation coping mechanism like learning to cope stress, adopting new lifestyle and identification of release of networks as well as improve health in stressful condition [10]. Leisure coping mechanism has the ability to develop coping behavior and perception against stress in lifelong with various dimensions such as leisure companionship, leisure relaxation and leisure to develop positive reactions, emotions and feelings, by nature, stress is considering negatively and adversely affects the physical and psychological health [25]. Leisure coping mechanism may improve and protects the healthy lifestyle, health and well-being with reference to a variety of aspects such as social psychology, the lifestyle of individuals and particular stressful conditions.

\section{Conclusion}

The data analyses found that one of the mediating model perform their significant role in between job stressors and job performance of LPEs at the college level. Therefore, the mediating role of relaxation coping was found greater and partial. The current study concluded that job stress such as working environment, workload and physical resources have significant and positive likewise the workload, working environment, and existing resources have a positive and significant effect on the job performance of the LPEs. The existing research also highlight that that different attributes of the job stress i.e. working environment, workload and physical resources are up to the mark and satisfactory. This empirical result indicated that relaxation coping technique play partial mediating role in-between job stress and job performance.

\section{Research Implications}

This research has identified certain important factors including working environment, workload, physical resources and required facilities in the perspective of job performance. These identified factors might be considered by the lecturer in physical education to get maximum job stress. The relaxation coping mechanism adopted by the LPE motivates them to achieve their pre-determined educational goals. The researcher only investigated the job stressors, coping mechanism (relaxation coping) and job performance of physical education teachers only at the college level, the job performance, relaxation coping and job performance of physical education teachers at other levels of education teachers were unknown and need to be investigated to unearth the in-depth information about the phenomena at all level. The future researcher may fill the gaps in the present study to explore the true picture of phenomena. The other provinces of Pakistan such as Punjab, Sindh, Baluchistan and Gilgit Baltistan may also be investigated 
in future to find out the overall position of job stressors, coping mechanisms and job performance in all over Pakistan.

\section{References}

[1] Ahmed, A., \&Ramzan, M. (2013). Effects of job stress on employees job performance a study on banking sector of Pakistan. IOSR Journal of Business and Management, 11 (6), 61-68.

[2] Amalu, M. (2014). Impact of workload induced stress on the professional effectiveness of secondary school teachers in Cross River State. Global Journal of Educational Research, $13(1), 15-22$

[3] Cakir, I. (2006). The use of video as an audio-visual material in foreign language teaching classroom. Turkish Online Journal of Educational Technology-TOJET, 5 (4), 67-72

[4] Clark, D. (2007). Classroom management challenges in the physical education class. European Physical Education Review, 3 (5), 19-24.

[5] Daun, H. (2004). Privatisation, decentralisation and governance in education in the Czech Republic, England, France, Germany and Sweden. International Review of Education, 50 (3-4), 325-346.

[6] Davis, E. A. (2006). Characterizing productive reflection among preservice elementary teachers: Seeing what matters. Teaching and teacher education, 22 (3), 281-301.

[7] De Carvalho, J. S., Pinto, A. M., \&Marôco, J. (2017). Results of a mindfulness-based social-emotional learning program on portuguese elementary students and teachers: a quasiexperimental study. Mindfulness, 8 (2), 337-350.

[8] Dyson, R., \&Renk, K. (2006). Freshmen adaptation to university life: Depressive symptoms, stress, and coping. Journal of clinical psychology, 62 (10), 12311244.

[9] Folkman, S., \& Moskowitz, J. T. (2000). Stress, positive emotion, and coping. Current directions in psychological science, 9 (4), 115-118.

[10] Fox, S., Spector, P. E., \& Miles, D. (2001). Counterproductive work behavior (CWB) in response to job stressors and organizational justice: Some mediator and moderator tests for autonomy and emotions. Journal of Vocational Behavior, 59 (3), 291-309.

[11] Gruskin, A., Williams, R. G., McCabe, E. R., Stein, F., Strickler, J., Chesney, R. W.,...\& Alden, E. R. (2000). Final report of the FOPE II Pediatric Subspecialists of the Future Workgroup. Pediatrics, 106 (5), 1224-1244.

[12] Hauge, L. J., Skogstad, A., \& Einarsen, S. (2010). The relative impact of workplace bullying as a social stressor at work. Scandinavian journal of psychology, 51 (5), 426-433.

[13] Hicks, C. M. (2009). Research Methods for Clinical Therapists E-Book: Applied Project Design and Analysis. Elsevier Health Sciences
[14] Idris, M. K. (2011). Over time effects of role stress on psychological strain among Malaysian public university academics. International Journal of Business and Social Science, 2 (9), 154-161.

[15] Kayastha, D. P., \&Kayastha, R. (2012). A study of occupational stress on job satisfaction among teachers with particular reference to corporate, higher secondary school of Nepal: Empirical study. Asian journal of management sciences and education, 1 (2), 52-62.

[16] Khan, S. H., Azhar, Z., Parveen, S., Naeem, F., \&Sohail, M. M. (2011). Exploring the impact of infrastructure, pay incentives, and workplace environment on employees performance (A case study of Sargodha University). Asian Journal of Empirical Research, 2 (4), 118-140.

[17] Levy, H. M. (2008). Meeting the needs of all students through differentiated instruction: Helping every child reach and exceed standards. The Clearing House: A Journal of Educational Strategies, Issues and Ideas, 81 (4), 161-164.

[18] Manabete, S. S., John, C. A., Makinde, A. A., \&Duwa, S. T. (2016). Job stress among school administrators and teachers in Nigerian secondary schools and technical colleges. Int $J$ Educ Learning Devel, 4, 1-9.

[19] Metzler, M. (2017). Instructional models in physical education. Routledge.

[20] Mouloud, K., Bougherra, B., \& Samir, B. F. (2016). Job satisfaction for physical education teachers and its relationship to job performance and organizational commitment. (3) 47-51.

[21] Okongo, R. B., Ngao, G., Rop, N. K., \&Nyongesa, W. J. (2015). Effect of Availability of Teaching and Learning Resources on the Implementation of Inclusive Education in Pre-School Centers in Nyamira North Sub-County, Nyamira County, Kenya. Journal of Education and Practice, 6 (35), 132-141.

[22] Rasberry, C. N., Lee, S. M., Robin, L., Laris, B. A., Russell, L. A., Coyle, K. K., \&Nihiser, A. J. (2011). The association between school-based physical activity, including physical education, and academic performance: a systematic review of the literature. Preventive medicine, 52, S10-S20.

[23] Salami, S. O. (2011). Job stress and burnout among lecturers: Personality and social support as moderators. Asian Social Science, 7 (5), 110.

[24] Srivastav, A. K. (2007). Stress in organizational rolesindividual and organizational implications. Icfaian Journal of Management Research, 6 (12), 64-74.

[25] Sun, Y (2015). Research on Development of Physical Fitness in Physical Education Teaching.

[26] Tulenan, S. (2015). The Effect of Work Environment and Compensation toward Employee Performance at the Office of State Assets and Auction Service Manado. Jurnal EMBA: Jurnal Riset Ekonomi, Manajemen, Bisnisdan Akuntansi, 3 (3), 672-682. 